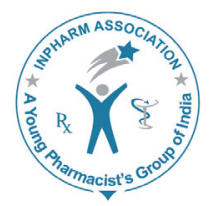

\title{
Attitude, Practice and Need Assessment of Emergency Contraception among Women of Reproductive Age Group in Delhi
}

\author{
Anjana Verma*, Satya Vir Singh, Vimal Kishore Gupta, Suneela Garg \\ and Jitendra Kumar Meena
}

Department of Community medicine, Maulana Azad Medical College, New Delhi-110002, India.

\section{ABSTRACT}

Background: Unintended pregnancy is an important public health issue in developing countries like India because of its association with adverse social and health outcomes. Emergency Contraception (EC) is a safe and effective way to prevent unplanned pregnancy. The objectives of this study were to assess the attitude, practices and do the need assessment of emergency contraception among the married women of 18 to 45 years in an urban area of Delhi. Methods: It was a community based cross sectional study, done in an urban locality in Central Delhi. A pretested semi-structured questionnaire was used to take the interview of eligible females. Results: $83.2 \%$ of the study subjects had favourable attitude towards the use of emergency contraception in future, if need arises. There was siginificant association of attitude with age, parity and contraceptive usage. Only $9 \%$ of the study subjects had ever used EC. Most of them, purchased emergency contraception from a chemist. I pill was found to be the most common EC used by the study subjects. The practice of EC was found to be associated with education, contraceptive usage and having knowledge about EC. Conclusion: Government health facilities were the first choice of study subjects for receiving the information and getting emergency contraceptive pills. However the unavailability of the emergency contraceptive pills at health centres and long waiting time in government health facilities were found to be the reasons for not going to the government health facilities for getting the emergency contraceptive pills.

Key words: Attitude, Emergency contraception, Need assessment, Practice, Urban area, Women.

\section{INTRODUCTION}

Worldwide around 80 million pregnancies each year are unintended and more than one-half result in induced abortion. About one-third (26.5 million) of unintended pregnancies each year result from incorrect use or failure of contraceptives. ${ }^{1}$ An estimated 80 million unintended pregnancies occured in 2012 in the developing

\begin{tabular}{|c|c|}
\hline \multicolumn{2}{|c|}{ Access this article online } \\
\hline Journal Sponsor & \multirow[b]{2}{*}{$\begin{array}{l}\text { Website: } \\
\text { www.jyoungpharm.org }\end{array}$} \\
\hline & \\
\hline www.p & $\begin{array}{l}\text { DOI: } \\
\text { 10.5530/jyp.2015.4.6 }\end{array}$ \\
\hline
\end{tabular}

world, resulting in 40 million abortions and 10 million miscarriages. ${ }^{2}$

In India, as per National Family Health Survey (NFHS-3), $56 \%$ of currently married women of age 15-49 years were using any method of contraception. Total unmet need for family planning was $13.2 \%$, out of which $6.3 \%$ was for spacing. Despite women's expressed desires to space their children, the condom is used by only $5 \%$, pill used by $3 \%$ and Intra uterine device by only $2 \%$ of women. ${ }^{3}$ Emergency contraception, thus, becomes an important back-up method for the couples who do not use contraception and when contraception fails, as when a condom breaks, pills are missed, or an IUD is dislodged. For these couples,

*Address for correspondence:

Dr.Anjana Verma, Reader, Post graduate student, Department of Community Medicine, Maulana Azad Medical College, New

Delhi-110002, India.E-mail: anjanaverma504@gmail.com 


\section{Attitude, practice and need assessment of Emergency contraception}

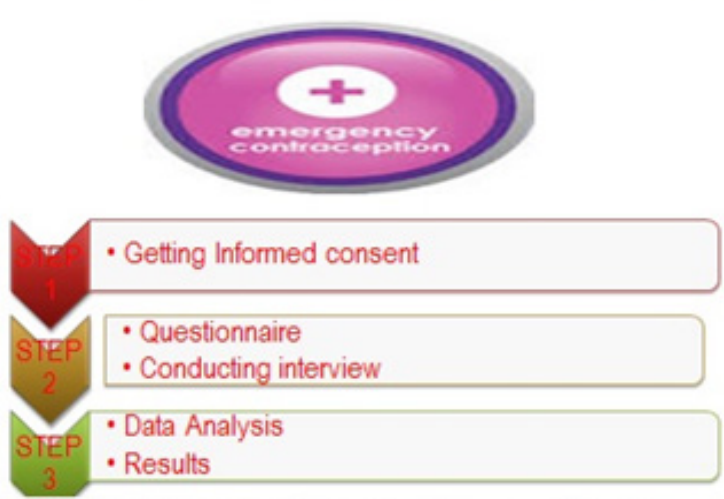

Attitude of the study subjects and need assessment about the emergency contraception

\begin{tabular}{|l|l|}
\hline Response & Percentage(\%) \\
\hline Attitude regarding use of EC & \\
Positive attitude & 83.2 \\
Negative attitude & 16.8 \\
\hline Reason for not using EC & \\
Side effects of pills & 21.7 \\
Religious reasons & 28.9 \\
No need since Cu T been inserted & 49.2 \\
\hline What place would you prefer for & \\
getting EC & \\
Chemist & 18.8 \\
Pvt practitioner & 4.4 \\
Govt. hospital & 76.8 \\
\hline
\end{tabular}

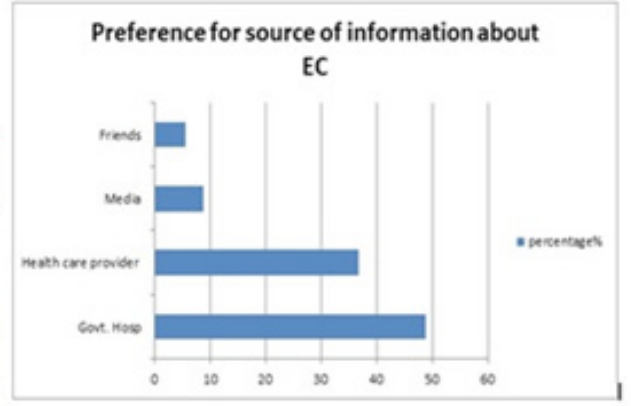

Practices of emergency contraception

\begin{tabular}{|l|l|}
\hline Item & Percentage(\%) \\
\hline Have you ever used EC & \\
Yes & 9.0 \\
No & 91.0 \\
\hline Place of getting EC & \\
Chemist & 89.2 \\
Private Practitioner & 8.1 \\
Govt hospital family & 2.7 \\
planning clinic & \\
\hline Opinion about cost & 91.9 \\
High Reasonable & 8.1 \\
\hline
\end{tabular}

Graphical Abstract

post-coital contraception provides a critical second chance to prevent an unwanted pregnancy. ${ }^{4}$

Emergency contraception is intended for occasional or emergency use only and not as a regular contraception. Situations of unprotected intercourse that demand the use of emergency contraception include failure of barrier methods such as slippage, breakage or misuse of condom, sexual assaults, failed coitus interruptus, two or more consecutive missed oral contraceptive pills, or simply because intercourse was unexpected and therefore contraception had not been used. ${ }^{3}$

Several contraceptive methods can be used to prevent pregnancy after an unprotected act of sexual intercourse. These methods include special doses of ordinary birth control pills as well as the insertion of an intra-uterine device (IUD). Emergency contraceptive pills (ECPs) must be taken within five days of unprotected sex. Depending on the method used, emergency contraception can reduce a women's risk of becoming pregnant from a single act of intercourse by $75 \%$ to $99 \% .^{4}$ Levonorgestrel-alone emergency contraception pills are very safe and do not cause abortion or harm future fertility. Side-effects are uncommon and generally mild. ${ }^{5}$ Emergency contraception (EC), a method of preventing pregnancy after unprotected sexual intercourse can play a unique role in providing women with a 'second chance' to prevent an unintended pregnancy. The emergency contraceptive pills have been introduced as part of the National Reproductive and Child Health (RCH) program in India (Ministry of Health and Family Welfare 2002). It has dramatically increased women's agency and ability to make informed choices regarding pregnancy and reproduction. Despite its potential, the use of EC in India remains low, probably due to limited knowledge about the method among both providers and users. $^{4}$

A study in a rural setting of Uttar Pradesh, in 2010 revealed that despite 65\% literacy among females, only $2 \%$ were aware of emergency contraception. Once the study subjects were aware of the availability of this method, all women expressed their willingness to use the emergency contraceptive pills in future, if the need arose. ${ }^{6}$ A study done by Fernandes et al in Udupi district of Karnataka, in Jan 2014 has revealed that majority of the married women of the reproductive age group (99.7\%) have had favourable attitude on the use of emergency contraceptives. ${ }^{7}$ Regarding the usage, a study done in Rohtak, Haryana by Dahiya et al in 2012, revealed that $8.8 \%$ of the women of reproductive age group attending postpartum center at Post Graduate Institute of Medical Sciences (PGIMS) out 
patient department had used EC pill and 84\% were willing to use emergency contraception if educated about it. ${ }^{8}$

The present study was carried out to assess the attitude and practices of emergency contraception among the married women of 18 to 45 years in an urban area of Delhi. Other objective was to do need assessment for source of information and availability of emergency contraceptives.

\section{METHODS}

Study Population was the married women in the age group of 18-45 years residing in the area. Taking the prevalence of awareness about emergency contraception among women in urban areas as $18.8 \% \%^{3}$ (According to NFHS-III), with a relative error of $20 \%$ total sample size was calculated to be 410.Sampling was done using the simple random sampling technique. A sample of 410 women was selected using the random number table from the list of eligible couples noted in the register, which is maintained by the Delhi Gate health centre in Darya ganj area. Investigation was carried out by the investigator, by paying house to house visits. During the house visits, investigator introduced herself to the eligible women, and explained the purpose and procedure of the study, and ensured complete confidentiality of their responses. Following this a written informed consent were obtained from the women for their inclusion as study participants. In case of women who refused to give their written informed consent for the participation in the study, the woman listed next on the list of eligible couples was contacted. For conducting the interview, a pretested, semistructured questionnaire was used to take the interview of eligible females. Questionnaire included questions to assess the socio economic status, reproductive characteristics, attitude, practice and need assessment regarding emergency contraception among the study subjects.

\section{ETHICS}

The purpose of the study was explained to all study participants; they were also informed that all of their responses are confidential and anonymous, and they have all the right not to be involved in the study or not to answer any of the questions.

\section{STATISTICS}

Data was analysed using SPSS version 17. Completed schedules were included for data processing and analysis. Percentage and proportions were calculated for knowledge and practice. Chi square and Fischer Exact test were used as tests of significance in univariate analysis. A p value of less than 0.05 was considered significant. The factors found significant in univariate analysis were then analysed in a multivariate logistic regression model. Adjusted odds ratios with the confidence intervals were calculated from the final model to quantify the association between the dependent and independent variable.

Dependent variables

- Attitude: Intention of using or recommending EC when a need arises. Intending to use or recommend is considered as a positive attitude, and no intention as a negative attitude

- Practice: Any previous history of EC usage

Independent variables

- Age (in years): different age groups: 18-25, 26-35, 36-45

- Education status: Illiterate and less than primary (upto $5^{\text {th }}$ ), Primary and above

- Socioeconomic status: Upto lower middle, Upper middle and above

- Number of children: Upto 2,>2

- Usage of any contraceptive method (condom, pills, CuT etc.): Yes, No

\section{RESULTS AND DISCUSSION}

In this study, a total of 420 currently married women aged 18-45 years residing in Darya ganj area were contacted, till the required sample of 410 women consented to participate in the study. This sample of 410 women was included in the study and were interviewed. Most of the study subjects were in the age group of 26-35 years and housewives by occupation. $157(38.3 \%)$ study subjects had history of abortion, out of which 120 (76.4\%) had abortion once where as, $37(23.6 \%)$ had abortion twice or more. Most common reason for abortion was unwanted pregnancy (80.9\%). There were 315 (76.8\%) study subjects who were using some method of contraception.

Table 1 shows attitude of the study subjects and need assessment about EC. There were 341(83.2\%) study subjects, who had positive attitude about EC. In this study $83.2 \%$ study subjects were found to have positive attitude about the use of emergency contraception. This prevalence is comparable to a study done by Nigam et al in Uttar Pradesh in 2010. ${ }^{6}$ Another study done in Rohtak, Haryana by Dahiya et al in 2012, revealed similar results, according to which, $84 \%$ of the women were willing to use emergency contraception if educated about it. ${ }^{8}$ Similar 


\begin{tabular}{|c|c|c|}
\hline Response & Number & Percentage (\%) \\
\hline \multicolumn{3}{|l|}{ Attitude regarding use of EC } \\
\hline $\begin{array}{l}\text { Positive attitude } \\
\text { Negative attitude }\end{array}$ & $\begin{array}{c}341 \\
69\end{array}$ & $\begin{array}{l}83.2 \\
16.8\end{array}$ \\
\hline \multicolumn{3}{|l|}{ Reason for not using EC } \\
\hline $\begin{array}{c}\text { Side effects of pills } \\
\text { Religious reasons } \\
\text { No need since Cu T been inserted }\end{array}$ & $\begin{array}{l}15 \\
20 \\
34\end{array}$ & $\begin{array}{l}21.7 \\
28.9 \\
49.2\end{array}$ \\
\hline \multicolumn{3}{|c|}{ What source would you prefer to have information about EC } \\
\hline $\begin{array}{c}\text { Mass media } \\
\text { Friends } \\
\text { Health care provider } \\
\text { Family planning clinic/Govt. } \\
\text { hospital/dispensary }\end{array}$ & $\begin{array}{c}30 \\
19 \\
125 \\
167\end{array}$ & $\begin{array}{c}8.8 \\
5.6 \\
36.7 \\
48.9\end{array}$ \\
\hline \multicolumn{3}{|c|}{ What place would you prefer for getting EC } \\
\hline $\begin{array}{c}\text { Chemist } \\
\text { Pvtpractitioner } \\
\text { Govt. hospital }\end{array}$ & $\begin{array}{c}64 \\
15 \\
262\end{array}$ & $\begin{array}{c}18.8 \\
4.4 \\
76.8\end{array}$ \\
\hline
\end{tabular}

Table 2: Attitude towards EC according to socio-demographic and obstetric characteristics of study subjects $(\mathrm{N}=410)$

\begin{tabular}{|c|c|c|c|}
\hline Characteristics & Total & $\begin{array}{l}\text { Positive attitude } \\
\text { towards EC, } N(\%)\end{array}$ & pvalue \\
\hline \multicolumn{4}{|l|}{ Age } \\
\hline $18-25$ & 101 & 96(95.05) & \multirow{3}{*}{$<0.001$} \\
\hline $26-35$ & 205 & $176(85.9)$ & \\
\hline $36-45$ & 104 & $69(66.3)$ & \\
\hline \multicolumn{4}{|l|}{ Education status } \\
\hline $\begin{array}{l}\text { Illiterate and less than } \\
\text { primary }\end{array}$ & 96 & $73(76.04)$ & \multirow[t]{2}{*}{0.040} \\
\hline Primary and above & 314 & $267(85.03)$ & \\
\hline \multicolumn{4}{|l|}{ Socioeconomic status } \\
\hline Upto lower middle & 247 & $195(78.9)$ & \multirow{2}{*}{0.005} \\
\hline Upper middle and above & 163 & $146(89.6)$ & \\
\hline \multicolumn{4}{|l|}{ Number of children } \\
\hline Upto2 & 215 & 195(90.7) & \multirow{2}{*}{$<0.001$} \\
\hline$>2$ & 195 & $146(74.9)$ & \\
\hline \multicolumn{4}{|l|}{ History of abortion } \\
\hline Yes & 157 & $140(89.2)$ & \multirow{2}{*}{0.011} \\
\hline No & 253 & $201(79.4)$ & \\
\hline \multicolumn{4}{|c|}{ Usage of contraceptive method } \\
\hline Yes & 315 & $269(85.4)$ & \multirow{2}{*}{0.016} \\
\hline No & 95 & $71(74.7)$ & \\
\hline
\end{tabular}

findings have been reported from the studies carried out in Cameroon (2007) and Ghana (2011). ${ }^{9,10}$

Study subjects, who refused to use emergency contraception were $20(28.9 \%)$, because of the religious reasons. This proportion is less as compared to the finding revealed in a study done by Irfan et al in Karachi, Pakistan (2009), which demonstrated that $36.2 \%$ of women stated they had objection due to religious values, $53.8 \%$ believed that religion does not influence its use, while $10 \%$ were unsure. ${ }^{11}$ This discrepancy can be attributed to the fact that this study was done in muslim based population and was not a community based study. These differences in methodology along with the differences in cultural beliefs can be the reason for the variation.

\section{Factors associated with the attitude towards EC}

Table 2 shows the factors associated with attitude towards use of EC. Table 3 shows the adjusted odds ratios and 95\% confidence intervals of the factors found to be associated with the attitude of emergency contraception among the 


\begin{tabular}{|c|c|c|c|}
\hline Characteristics & AOR & $95 \% \mathrm{Cl}$ & $P$ value \\
\hline \multicolumn{4}{|l|}{ Age group } \\
\hline $36-45$ & 1.00 & - & - \\
\hline $26-35$ & 2.005 & $1.043-2.875$ & 0.001 \\
\hline $18-25$ & 2.384 & $1.501-3.786$ & $<0.001$ \\
\hline \multicolumn{4}{|l|}{ Education status } \\
\hline $\begin{array}{l}\text { Illiterate and less than } \\
\text { primary }\end{array}$ & 1.00 & - & \multirow[t]{2}{*}{0.130} \\
\hline Primary and above & 1.485 & $0.891-2.475$ & \\
\hline \multicolumn{4}{|c|}{ Socioeconomic status } \\
\hline Upto lower middle & 1.00 & - & \multirow[b]{2}{*}{0.097} \\
\hline $\begin{array}{l}\text { Upper middleand } \\
\text { above }\end{array}$ & 1.435 & $0.937-2.197$ & \\
\hline \multicolumn{4}{|l|}{ Number of children } \\
\hline Upto2 & 1.00 & - & \multirow{2}{*}{0.002} \\
\hline$>2$ & 0.261 & $0.113-0.601$ & \\
\hline \multicolumn{4}{|l|}{ History of abortion } \\
\hline Yes & 1.00 & & \multirow{2}{*}{0.709} \\
\hline No & 1.084 & $0.708-1.660$ & \\
\hline \multicolumn{4}{|l|}{ Contraceptive use } \\
\hline No & 1.00 & - & \multirow{2}{*}{0.026} \\
\hline Yes & 2.075 & $1.091-3.949$ & \\
\hline
\end{tabular}

study subjects from a final multivariate logistic regression model. In this study, the positive attitude towards EC was higher among the lower age group (18-25 years), it decreases with age. This is comparable to the findings of the other studies. ${ }^{912-14}$ The study subjects with upto 2 children were found to be associated with higher odds of having positive attitude towards EC than the study subjects having more than 2 children. It can be attributed to the fact, that the study subjects who believe in the small family norm are more likely to have positive attitude towards the future use of EC. Similar findings were observed in a study done by Wegene et al. ${ }^{14}$ The women who were using some method of contraception were twice as likely to have a positive attitude towards EC as compared to the study subjects who were not using any contraception. This is because, study subjects who are using any family planning method are aware about the contraceptive failure and are concerned about preventing any unwanted pregnancy. So, they are willing to use EC in future if need arises.

\section{Need assessment for the source of information and availability of EC}

In this study, most of the study subjects, preferred either family planning clinic $(48.9 \%)$ or a health care provider $(36.7 \%)$ for getting information about EC. This can be attributed to the fact that study subjects were aware that informal sources such as friends, relatives and audio visual media can be associated with misinformation or incomplete

\begin{tabular}{|ccc|}
$\begin{array}{c}\text { Table 4: Practices of emergency contraception } \\
\text { Item }\end{array}$ & $\begin{array}{l}\text { Number } \\
\text { Percentage (\%) }\end{array}$ \\
$\begin{array}{c}\text { Have you ever used EC } \\
\text { Yes }\end{array}$ & 37 & 9.0 \\
No & 373 & 91.0 \\
\hline $\begin{array}{c}\text { Place of getting EC } \\
\text { Chemist }\end{array}$ & 33 & 89.2 \\
\hline $\begin{array}{c}\text { Pvt. Practitioner } \\
\text { Govt. hospital/family } \\
\text { planning clinic }\end{array}$ & 3 & 8.1 \\
\hline $\begin{array}{c}\text { Cost of EC pill } \\
\text { 60 Rupees }\end{array}$ & 1 & 2.7 \\
\hline 80 Rupees & 3 & \\
\hline 100 Rupees & 13 & 8.1 \\
\hline dontknow & 15 & 35.1 \\
\hline Opinion about cost & 6 & 40.5 \\
\hline High & 34 & 16.2 \\
\hline Reasonable & 3 & 91.9 \\
\hline
\end{tabular}

information, where as medical sources are reliable. The evidence suggests that patients request information about a medication's indication, expected benefits, duration of therapy, and a meticulous list of potential adverse effects. ${ }^{15}$ This finding differs from the finding revealed in a study done by Irfan et al in Karachi, Pakistan (2009) that wide advertisement of emergency contraception was favoured by $72.5 \%$ women, while $25 \%$ were against increased advertisement and $2.5 \%$ were neither against nor in favour of advertisements. ${ }^{11}$ Differences in methodology and beliefs of the community are the possible reasons for this variation. 


\begin{tabular}{|c|c|c|c|}
\hline Characteristics & Total & Have used EC, N(\%) & $p$ value \\
\hline \multicolumn{4}{|l|}{ Age group } \\
\hline $18-25$ & 101 & $8(7.9)$ & \multirow{3}{*}{0.001} \\
\hline $26-35$ & 205 & $26(12.7)$ & \\
\hline $36-45$ & 104 & $3(2.9)$ & \\
\hline \multicolumn{4}{|l|}{ Education status } \\
\hline $\begin{array}{l}\text { Illiterate and less than } \\
\text { primary }\end{array}$ & 96 & $3(3.1)$ & \multirow[t]{2}{*}{0.021} \\
\hline Primary and above & 314 & $34(10.8)$ & \\
\hline \multicolumn{4}{|c|}{ No. of family members 4 or less } \\
\hline$>4$ & 137 & $6(4.4)$ & \multirow{2}{*}{0.020} \\
\hline$>4$ & 273 & $31(11.4)$ & \\
\hline \multicolumn{4}{|l|}{ Number of children } \\
\hline Upto2 & 215 & $13(6)$ & \multirow{2}{*}{0.027} \\
\hline$>2$ & 195 & 24(12.3) & \\
\hline \multicolumn{4}{|c|}{ Usage of contraceptive method by study subject } \\
\hline Yes & 315 & $35(11.1)$ & \multirow{2}{*}{0.019} \\
\hline No & 95 & $3(3.2)$ & \\
\hline \multicolumn{4}{|c|}{ Have knowledge about EC } \\
\hline Yes & 185 & $35(18.9)$ & \multirow{2}{*}{$<0.001$} \\
\hline No & 225 & $2(0.9)$ & \\
\hline
\end{tabular}

$76.8 \%$ of the study subjects preferred govt. hospital to get EC, where as $64(18.8 \%)$ study subjects said that they would prefer to purchase EC from a chemist and $15(4.4 \%)$ study subjects preferred a private practitioner. Since, $60 \%$ of the study subjects in our study belonged to lower middle class and lower socio-economic status, this can be attributed to their preference for Government health services.

Table 4 shows the practice regarding EC among the study subjects. Only $37(9.0 \%)$ of the study subjects have ever used emergency contraception. Our finding is comparable to the study done in Rohtak, Haryana by Dahiya et al in 2012 , which revealed that $8.8 \%$ of the women had used EC pill. ${ }^{8}$ Relwani et al (2012) ${ }^{12}$ reported much lower proportion of the female students $(5.7 \%)$ having used emergency contraception in an engineering college in Nagpur district, Maharashtra. The probable reason for this is the difference in the study population and since the study population in that study were college students, so it can be possible that the study subjects did not provide honest answers to the questions, since the survey involved a sensitive matter (i.e. sex). The results in our study are comparable to the reported data from the 2006-2010 National Survey of Family Growth, Centres for disease control and prevention (CDC), according to which, $11 \%$ of the sexually experienced women aged 15-44 years had ever used emergency contraception. ${ }^{16}$

\section{Factors associated with the practices towards EC}

Table 5 shows the factors associated with the practices towards EC. Table 6 shows the adjusted odds ratios and $95 \%$ confidence intervals of the factors found to be associated with the positive attitude towards EC among the study subjects from final multivariate logistic regression model. Respondent's education status was found to be significantly associated with the usage of EC. The finding is in consistency with data from the 2006-2010 National Survey of Family Growth, Centres for disease control and prevention (CDC), which revealed that the ever-use of emergency contraception increased with educational attainment. $^{16}$

Study subjects who were using some method of contraception were four times more likely to have used EC as compared to the study subjects who were not using any contraceptive method. This finding can be attributed to the fact that the study subjects who were using some method of contraception, used EC when there was either the condom breakage or the non use of any contraceptive method.

The knowledge about emergency contraception was significantly associated with its usage among the study subjects. This finding in the present study is similar to another study carried out in Southern Ethiopia (2011), where 


\begin{tabular}{|c|c|c|c|}
\hline Characteristics & AOR & $95 \% \mathrm{Cl}$ & $P$ value \\
\hline \multicolumn{4}{|l|}{ Age group } \\
\hline $18-25$ & 1.00 & - & - \\
\hline $26-35$ & 1.58 & $0.79-3.001$ & 0.174 \\
\hline $36-45$ & 1.650 & $0.819-3.322$ & 0.181 \\
\hline \multicolumn{4}{|l|}{ Education status } \\
\hline $\begin{array}{c}\text { Illiterate and less than } \\
\text { primary }\end{array}$ & 1.00 & - & \multirow[t]{2}{*}{0.018} \\
\hline Primary and above & 5.921 & $1.351-25.940$ & \\
\hline \multicolumn{4}{|c|}{ No. of family members 4 or less } \\
\hline \multirow{2}{*}{$>4$} & 1.00 & - & \multirow{2}{*}{0.205} \\
\hline & 2.114 & $0.664-6.726$ & \\
\hline \multicolumn{4}{|l|}{ Number of children } \\
\hline Upto2 & 1.00 & - & \multirow{2}{*}{0.261} \\
\hline$>2$ & 1.832 & $0.638-5.261$ & \\
\hline \multicolumn{4}{|l|}{ Contraceptive use } \\
\hline No & 1.00 & - & \multirow{2}{*}{0.038} \\
\hline Yes & 4.771 & $1.093-20.832$ & \\
\hline \multicolumn{4}{|l|}{ Have heard of EC } \\
\hline No & 1.00 & - & \multirow{2}{*}{$<0.001$} \\
\hline Yes & 26.500 & $6.106-115.014$ & \\
\hline
\end{tabular}

use of emergency contraceptive was significantly higher among students who have good knowledge about EC.13

The present study revealed that $8.7 \%$ of the Muslim study subjects had ever used EC as compared to $9.8 \%$ of Hindu study subjects. The difference in religion was not significantly associated with the use of EC. The proportion of Muslim women who had ever used EC is higher than that found in the study done by Irfan et al in Karachi, Pakistanwhich demonstrated that only $3.25 \%$ of the muslim women had practised emergency contraception. ${ }^{11}$ Similar finding was revealed in a study done in Pakistan, by Naz et al, in 2009, which revealed that, only $2 \%$ of the women aged 18 to 45 years visiting Gynaecology OPD had practised emergency contraception. ${ }^{17}$ This variation can be attributed to the differences in methodology and cultural beliefs.

\section{CONCLUSION}

Most of the study subjects $(83.2 \%)$ in our study had favourable attitude towards the use of emergency contraception in future, if need arises. The reasons for not using the emergency contraception among the rest of the study subjects were found to be related to religion and fear of side effects of pills. Government health facilities were the first choice of study subjects for receiving the information and getting emergency contraceptive pills. However the unavailability of the emergency contraceptive pills at health centres and long waiting time in government health facilities were found to be the reasons for not going

to the government health facilities for getting the emergency contraceptive pills. The use of emergency contraception was very low i.e, only 9\% among the study subjects. Most of them, purchased emergency contraception from a chemist. There is need to educate women about the available methods of emergency contraception and correct timing of its use. The women should be counselled about the regular methods of contraception and to keep the emergency contraception in reserve for emergency purpose only. For emergency contraception to become a true choice, women must have access to the available option within the short timeframe permitted by the method.

\section{CONFLICTS OF INTEREST}

Authors declared there is no Conflict of interest.

\section{ACKNOWLEDGEMENTS}

We are thankful to the staff at health centre, Delhi Gate, Darya Ganj.

\section{ABBREVIATIONS}

CDC: Centre for disease control and prevention

EC: $\quad$ Emergency Contraception

IUD: Intrauterine Device

NFHS: National Family Health Survey

PGIMS: Post Graduate Institute of Medical Sciences 


\section{Highlights of Paper}

- Emergency contraceptives are back-up methods of preventing pregnancy after unprotected sexual intercourse.

- Most of the study subjects in our study had favourable attitude towards the use of emergency contraception in future, if need arise.

- Government health facilities were found to be the first choice of study subjects for receiving the information and getting emergency contraceptive pills.

- Only $9 \%$ of the study subjects had ever used emergency contraception.

\section{Author Profile}

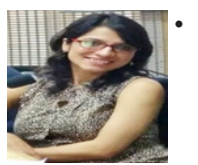

Dr.Anjana Verma : Post graduate in Community Medcine from Maulana Azad Medical College, New Delhi. She has 4 nos. of journal papers. Lifetime member of Indian Public health Association (IPHA), Indian Association of Preventive and Social Medicine (IAPSM) and Indian Association of Adolescent Health (IAAH).

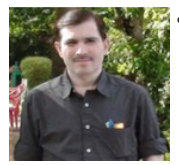

Dr.Satya Vir Singh : Working as a Professor in department of Community Medcine, Maulana Azad Medical College, New Delhi. He has many publications in National and International journals.Lifetime member of Indian Public health Association (IPHA) and Indian Association of Preventive and Social Medicine (IAPSM).

\section{RFERENCES}

1. World Population Data Sheet. 2010. Population Reference Bureau; 2010.

2. Singh S, Darroch JE. Adding it up: the costs and benefits of contraceptive services; estimates for 2012. New York: Guttmacher Institute; 2012. Available online at_http://www.guttmacher.org/pubs/ AIU-2012-estimates.pdf.

3. Bhat PNM, Arnold F, Gupta K, Kishor S, Parasuraman S, Arokiasamy $P$ et al. National Family Health Survey (NFHS-3) 2005-2006 [internet]. Updated on 2007, Oct. 15 [cited on 2014, Feb 21]. Available from: http://hctv.org/india/nfhs-3-chapter-05family-planning.pdf

4. Nayyar A. Health and Population - Perspectives and Issues. Increasing access to emergency contraception in India 2000; 23(3): 123-33.

5. WHO. Emergency contraception: Fact sheet; 2012.[ cited 2014, Feb 21]. Available from: www.who.int/mediacentre/factsheets/ fs244/en

6. Nigam A, Maheshwari N, Prakash A. Knowledge of emergency contraception and contraceptive practices. Representative study from rural Uttar Pradesh. Indian J Community Med. 2010; 35(3): 449-50.

7. Fernandes P, D'Souza SRB, Karkada S. Knowledge and attitude of married women in the reproductive age group regarding emergency contraception in selected rural areas of Udupi district, Karnataka. JKIMSU. Jan 2014; 3(1): 64-8.

8. Dahiya K, Mann S, Nanda S. Women's Knowledge and Opinions regarding Emergency Contraception. JSAFOG. 2012; 4(3):151-4.

9. Kongnyuy EJ, Ngassa P, Fomulu N, Wiysonge CS, Kouam L, Doh
AS. A survey of knowledge, attitudes and practice of Emergency Contraception among university students in Cameroon. BMC Emerg Med. 2007; 7(1): 7.

10. Baiden F, Awini E, Clerk C. Perception of university students in Ghana about emergency contraception. Contraception. 2002; 66(1): 23-6.

11. Irfan F, Karim SI, Hashmi S, Ali Sajid, Ali SA. Knowledge of emergency contraception among women of childbearing age at a teaching hospital of Karachi. J Pak Med Assoc. 2009 Apr; 59(4): 237-9.

12. Relwani N, Saoji A, Kasturwar NB, Nayse J, Junaid M, Dhatrak P. Emergency contraception: Knowledge, attitude and practices of engineering college girls in Nagpur district of Central India. Natl J Community Med. 2012; 3(1): 14-9.

13. Worku A. Knowledge, attitude and practice of emergency contraceptives among female college students in Arba Minch Town, Southern Ethiopia.Ethiop. J. Health Dev. 2011; 25(3): 176-83.

14. Wegene T, Fikre E. Knowledge, attitude and practice on Emergency Contraceptives among female university students in Addis Ababa, Ethiopia. Ethiop J Health Dev. 2007; 21(2): 111-6.

15. Jeetu G, Girish T. Prescription Drug Labeling Medication Errors: A Big Deal for Pharmacists. J Young Pharm. 2010; 2(1): 107-11.

16. National Survey of Family Growth, 1995, 2002, and 2006-2010[Internet]. CDC/NCHS; 2010[cited 2014 Mar 6]. Available from: http://www.cdc.gov/nchs/data/databriefs/db112_tables.pdf\#1.

17. Naz S, Tayyab S, Ali L, Yasir R. Emergency contraception: Knowledge and Attitude among females. Journal of Surgery Pakistan (International) 2009; 14(2): 89-92. 